\title{
Osteogenic differentiation characteristics of hip joint capsule fibroblasts obtained from patients with ankylosing spondylitis
}

\author{
Nan Jiang ${ }^{1}$, Hong-Xiao Liu ${ }^{2}$, Hui-Ying Liang ${ }^{3}$, Xing-Hua Feng ${ }^{2}$, Ben-Yong Liu ${ }^{4}$, Ying-Yan Zhou ${ }^{5}$ \\ ${ }^{1}$ Department of Nephrology and Rheumatology, Second Affiliated Hospital of Tianjin University of TCM, Tianjin, China; ${ }^{2}$ Department of \\ Rheumatology, Guang'anmen Hospital, China Academy of Chinese Medical Sciences, Beijing, China; ${ }^{3}$ Department of Traditional Chinese Medicine, \\ Zhongshan City People's Hospital, Zhongshan, China; ${ }^{4}$ Department of TCM internal medicine, Beijing Massage Hospital, Beijing, China; \\ ${ }^{5}$ Department of Rheumatology, Guangdong Provincial Hospital of Chinese Medicine, Guangzhou, China \\ Contributions: (I) Conception and design: HX Liu; (II) Administrative support: XH Feng; (III) Provision of study materials or patients: N Jiang, HY \\ Liang; (IV) Collection and assembly of data: N Jiang, HX Liu, HY Liang, BY Liu (V) Data analysis and interpretation: N Jiang, YY Zhou; (VI) \\ Manuscript writing: All authors; (VII) Final approval of manuscript: All authors. \\ Correspondence to: Hong-Xiao Liu. Department of Rheumatology, Guang'anmen Hospital, China Academy of Chinese Medical Sciences, No. 5, Bei \\ Xian Ge Street, Xicheng District, Beijing 100053, China. Email: liuhongxiao_123@163.com.
}

\begin{abstract}
Background: Autoimmune disease are fairly common and one that has an excessive degree of disability is Ankylosing spondylitis (AS). As the main cells in connective tissues, fibroblasts may play important roles in AS ossification. The conducted research aims to establish the osteogenic disparity characteristics of fibroblasts cultured in vitro, obtained via AS patients hip joint capsule, as well as investigating the pathological osteogenic molecular workings of AS.

Methods: AS patients hip joint capsules were acquired and fracture patients as the control with the finite fibroblast line were established by using tissue culture method. AS fibroblast proliferation, cycle and apoptosis, expression of osteogenic marker genes, osteogenic phenotypes, and the activation degree of the bone morphogenetic protein (BMP)/Smads signalling pathway were detected by flow cytometry, western blotting and real-time fluorescent quantitative polymerase chain reaction.

Results: Proliferative activity in AS fibroblasts were abnormally high, and the apoptotic rate decreased. Compared with normal fibroblasts, the mRNA expression of osteogenic marker genes, expression of osteogenic phenotypes, protein expression of core-binding factor a1 (Cbfa1), Smad1, Smad4, Smad5, phosphorylated (p) Smad1, and pSmad5 in AS fibroblasts were higher; however, the expression of Smad6 was lower. Moreover, recombinant human bone morphogenetic protein-2(rhBMP-2) stimulated Cbfa1 expression by normal and AS fibroblasts through the BMP/Smads signalling pathway.

Conclusions: The fibroblasts of hip joint capsules in patients with AS cultured in vitro have biologic characteristics of osteogenic differentiation and may be important target cells of AS ossification. The Activated BMP/Smads signalling pathway could potentially be a mechanism relating to fibroblasts differentiating into osteoblasts and an ossification mechanism for AS.
\end{abstract}

Keywords: Ankylosing spondylitis (AS); osteogenic differentiation; fibroblasts; BMP/Smads signal pathway

Submitted Oct 23, 2020. Accepted for publication Feb 08, 2021.

doi: $10.21037 /$ atm-20-7817

View this article at: http://dx.doi.org/10.21037/atm-20-7817

\section{Introduction}

Known as a refractory rheumatic disease, ankylosing spondylitis (AS), is defined as inflammation of the sacroiliac joints as well as spine which can also affect peripheral joints, particularly hip joints. Skeletal changes in AS are characterized by the concomitant presence of inflammatory bone destruction, as well as reparative bone hyperplasia (1). Pathological osteogenesis may cause progressive ankylosis 
of the spine and peripheral joints, leading to movement disorders, or even the permanent loss of active ability, and can seriously affect patients' life and work, which is the main cause of disability among AS patients. Therefore, it is important to improve the prognosis of AS patients to determine the pathological osteogenic molecular mechanism and to provide effective treatment to inhibit or delay ossification.

The connective tissue that surrounds the vertebral column and joints are ones that are ossified in AS with fibroblasts being the major cell component of the tissue. Fibroblasts and osteoblasts both derive from mesenchymal cells of mesodermal and have partially overlapping phenotypes and similar differentiation pathways (2). These form the biologic basis of fibroblasts differentiating into osteoblasts. Fibroblasts can express osteogenic activity under special conditions and stimulate specific induction factors in special circumstances (3). Fibroblasts have osteogenic potential and can form bone in vitro in an induced environment (4). Therefore, it can be hypothesized that fibroblasts of AS patients are likely to be target cells of AS ossification and play important roles in AS ossification.

Cellular differentiation is the result of the sequential expression of different genes. When the regulation mechanism of cells changes or under specific stimulation conditions, fibroblasts then start to exhibit osteogenic marker genes causing discrimination to osteoblasts (2). A core osteoblast-specific transcription factor/regulator in osteoblast discrimination that can differentiate mesenchymal cells into osteoblasts and inhibit their differentiation into adipocytes and chondrocytes is corebinding factor a1 (Cbfa1) (5). In addition, the expression of osteoblast-related genes such as alkaline phosphatase (ALP), osteocalcin (OC), and type I collagen can also be regulated (6-8), thereby resulting in the enhancement of expressed osteogenic phenotypes.

Fibroblasts have the potential to differentiate into osteoblasts showed by expressions of osteogenic marker genes. However, their activation needs particular cytokines stimulated. One kind of supreme cytokine is bone morphogenetic proteins (BMPs). It can cause bone and cartilage establishment thereby controlling expression and/ or function of transcription factors via stimulating Smad signalling during this process (9). By managing expressed Cbfa1 within the nucleus of the cell, BMPs are able to promote cells that are in differentiated mesenchymal and inverse this process into bone lineage cells. They are also key in promoting differentiation of precursor to bone-cartilage cells $(10,11)$. The strongest osteogenic capacity among all BMPs which can induce osteogenic differentiation individually is BMP-2. The addition of BMP-2 can vastly increase OC and BMP-2 expressed temporarily is required and adequate to irrevocably promote bone production $(12,13)$. BMP can specifically bind to and activate receptors in the target cell membrane, and then transfer signals from the cytoplasm to the nucleus mainly through receptor substrate Smad family proteins. Among the Smad family proteins, Smad1, Smad4, and Smad5 are closely related to bone metabolism (9), and Smad6 plays an important role in a negative feedback loop regulating BMP signalling (14). Activated Smad protein complexes enter the nucleus, closely integrate with target genes, initiate the transcription of target genes, and are involved in the transduction of BMP signalling.

The AS ossification mechanism appears to be that fibroblasts as osteogenic precursor cells and BMPs as osteogenic inducers activate AS fibroblasts in the BMP/ Smads signal transduction pathway This then regulates expressed osteogenic marker genes, resulting in AS fibroblast osteogenic differentiation.

Therefore, in the present study, we established a finite fibroblast line in vitro, which was derived from AS patients. We analyzed the osteogenic differentiation characteristic of AS fibroblasts by observing their proliferation, cycle and apoptosis, the expression of Smad family proteins, osteogenic marker genes and osteogenic phenotypes, and the activation degree of the BMP/Smads signal transduction pathway under rhBMP-2 inducement to explore the pathological osteogenic molecular mechanism of AS.

We present the following article in accordance with the MDAR reporting checklist (available at http://dx.doi. org/10.21037/atm-20-7817).

\section{Methods}

\section{Patients}

In the study conducted, hip joint capsules were utilized for fibroblast culturing. These were provided by 10 individual patients with AS that have undergone total hip replacement as well as 10 transcervical fracture individuals and prohibiting those with connective tissue disease. The specimens were operation waste and complied with ethical requirements; All processes completed that involved human contributors in regards to the current 
piece of research followed the Declaration of Helsinki (as revised in 2013). The Ethics Committee of Guang'anmen Hospital, China Academy of Chinese Medical Sciences (No.: 2011-028) has also given approval to the research conducted. And all patients provided signed informed consent. All patients were male inpatients at the Arthritis Clinic and Research Centre of Peking University People's Hospital and the Orthopedic Department of Peking University Third Hospital and aged $20-60$ years. Hip joint implants were taken from those who were submitted to hip substitution. The specimen was submerged into cultural medium immediately after extraction and shipped to the cell room.

\section{Cell cultures}

Primary culture used for fibroblasts gained from hip joint capsules was adherent culture. All the work was done in the purification workbench. First, $0.01 \mathrm{M}$ sterile phosphatebuffered saline (PBS; pH 7.4) was used to rinse tissue pieces repeatedly. Samples were then sliced into $1-\mathrm{mm}^{3}$ sections then put into $100 \mathrm{~mL}$ culture flasks which consist of were cut into pieces and a high-glucose Dulbecco's modified Eagle's medium (DMEM) (Gibco, Grand Island, USA) which contains $20 \%$ fetal bovine serum (FBS; HyClone, Logan, Utah, USA). The samples were then incubated in $5 \% \mathrm{CO}_{2}$ at $37{ }^{\circ} \mathrm{C}$. As soon as cells in the culture begin to appear and develop into $80 \%$ confluence, $0.25 \%$ trypsin (Sigma, Birmingham, Michigan, USA) was added for digestion, passaged at 1:1 for the first generation and again at $1: 2$ or $1: 3$. DMEM accompanied by $10 \%$ FBS within the subculture. All fibroblasts were used in passage 3 experiments outlined below.

\section{Assessment of fibroblast proliferation with Cell Counting Kit-8 (CCK-8)}

96-well cell culture plate was used to directly plant passage 3 cells at $1 \times 10^{4} / \mathrm{mL}$ density, $100 \mu \mathrm{L}$ per well at $37^{\circ} \mathrm{C}$ in a $5 \% \mathrm{CO}_{2}$ incubator for 6 days ( $\mathrm{n}=5$ wells/group). After cells adherent, the CCK- 8 was performed on 5 wells to assay for proliferation every $24 \mathrm{~h}$ and draw a growth curve. The medium was removed, and a combination of $100 \mu \mathrm{L}$ DMEM and $10 \mu \mathrm{L}$ CCK-8 (Dojindo, Kumamoto, Japan) was incorporated into individual wells. The cells were then put into incubation for $30 \mathrm{~min}$ under $37^{\circ} \mathrm{C}$ conditions with the absorbance measured with a microplate reader at $450 \mathrm{~nm}$.

\section{Analysis of cell cycle with propidium iodide (PI) by flow cytometry}

The assay was performed on the fibroblasts from patients with AS and normal fibroblasts at passage 3. First, a singlecell suspension was prepared. Cells were then washed twice in pre-cooled PBS, the fluid was removed, and precooled $70 \%$ ethyl alcohol was added. Cultures were incubated overnight at $4{ }^{\circ} \mathrm{C}$. The following day, the fixed cells were centrifuged and the ethyl alcohol was removed. PBS was used to rinse the cells twice and digested in $20 \mu \mathrm{L} / \mathrm{mL}$ RNase A for $30 \mathrm{~min}$ at $37^{\circ} \mathrm{C}$, and then incubated with PI (Sigma, Birmingham, Michigan, USA) at a terminal density of $50 \mu \mathrm{L} / \mathrm{mL}$ for $1 \mathrm{~h}$ at $4{ }^{\circ} \mathrm{C}$. After filtration using a 300 screen cloth, the cells were assayed by FACScan flow cytometry (Becton, Dickinson and Company, Franklin Lakes, New Jersey, USA). The fluorescence histograms involving at least 20,000 cells were obtained by Cell Quest software (Sebring, FL, USA). Following analysis utilizing ModFit LT 2.0 software (Verity Software House, Topsham, ME, USA), the percentage of DNA compositions in the nucleus were detected at different phases. The experiments were performed 3 times.

\section{Analysis of cell apoptosis through Annexin $V$ assay by flow cytometry}

The assay was performed on the fibroblasts at passage 3 . First, a single-cell suspension was prepared at a density of $1 \times 10^{6} / \mathrm{mL}$. PBS was used to rinse cells before resuspension in $200 \mu \mathrm{L}$ binding buffer; $10 \mu \mathrm{L}$ Annexin V-fluorescein isothiocyanate $(20 \mu \mathrm{g} / \mathrm{mL}$; Beijing Biosea Biotechnology, Beijing, China) and $5 \mu \mathrm{L}$ PI $(50 \mu \mathrm{g} / \mathrm{mL})$ (Sigma, USA) were added and mixed lightly. The cultures reacted for $15 \mathrm{~min}$ under dark and room temperature conditions. Detection via cytometry was done after the addition of $300 \mu \mathrm{L}$ binding buffer. The experiments were performed 3 times.

\section{Analysis of ALP activity}

The assay was performed on the fibroblasts at passage 3 . First, a single-cell suspension was prepared at $3 \times 10^{4} / \mathrm{mL}$ concentration and before seeding onto a $24-$ well cell culture plate $\left(500 \mu \mathrm{L}\right.$ each well) and incubated in $5 \% \mathrm{CO}_{2}$ at $37^{\circ} \mathrm{C}$. The solution was refreshed every second day. On the third day, cell lysis buffer was added to 5 wells of each group and the protein mass was determined using a total protein quantification kit (Nanjing Jiancheng Bioengineering Institute, Nanjing, China). The concentration of phenol 
in protein from 5 wells of each group was examined by chromatography via the use of ALP detection kit (Nanjing Jiancheng Bioengineering Institute, China). The activity unit of one ALP at is defined as each gram of protein at $37^{\circ} \mathrm{C}$ react for $15 \mathrm{~min}$ can produce $1 \mathrm{mg}$ phenol.

\section{Analysis of collagen I and $O C$ in the supernatant}

Assay was performed on the fibroblasts at passage 3. First, a single-cell suspension of $1.5 \times 10^{4} / \mathrm{mL}$ concentration was prepared and seeded onto a 96-well cell culture plate $200 \mu \mathrm{L}$ each well and incubated in $5 \% \mathrm{CO}_{2}$ at $37^{\circ} \mathrm{C}$. The solution was refreshed every second day. On the third day, hydroxyproline of cells from 5 wells of each group was analyzed by chromatography using a hydroxyproline detection kit (Nanjing Jiancheng Bioengineering Institute, China) to detect the concentration of type I collagen in the supernatant. A concentration of $3 \times 10^{4} / \mathrm{mL}$ cells was also planted onto a 24-well cell culture plate $500 \mu \mathrm{L}$ each well, and every 5 wells were assigned to one group. On the third day, the supernatants were concentrated and lyophilized, and then the concentration of OC was detected using an OC detection kit (Beijing East Asian Radioimmunoassay Institute, Beijing, China) by radioimmunoassay.

\section{Cbfa 1 and $O C$ expressed in $m R N A$ identified by real-time polymerase chain reaction (RT-PCR)}

6-well cell culture plate was used to directly plant passage 3 fibroblasts at $6 \times 10^{4} /$ well concentration. RNA isolation was accomplished with the addition of TRIzol reagent (Invitrogen, Carlsbad, California, USA) into individual wells. Housekeeping gene $\beta$-actin was utilized as the control in order to carry out reverse-transcription real-time PCR. The following oligonucleotide primer (5' to 3 ' sequences) was used for the PCR analysis: Cbfa $1 \alpha$ sense: CAG CCA CCT TTA CTT ACA CCC and Cbfa1 $\alpha$ anti-sense: CAG CGT CAA CAC CAT TC (306-bp product); OC $\alpha$ sense: AGG GCA GCG AGG TAG TGA and OC $\alpha$ anti-sense: CCT GAA AGC CGA TGT GGT (150-bp product). Cbfa 1 and $\mathrm{OC}$ sense and anti-sense primers were first incubated at $95^{\circ} \mathrm{C}$ for $5 \mathrm{~min}$ before amplification in cycling parameters sated below: cycle 45 times for $30 \mathrm{~s}$ at $95^{\circ} \mathrm{C}$ and then $30 \mathrm{~s}$ at $58^{\circ} \mathrm{C}$ before elongation for $30 \mathrm{~s}$ at $72{ }^{\circ} \mathrm{C}$. After 45 cycles, elongation was then undertaken with the primers for $8 \mathrm{~min}$ at $72{ }^{\circ} \mathrm{C}$. All actions were performed on a computer connected to PCR equipment, and the fluorescent signals of every cycle were recorded automatically and a curve drawn. Digitized images were then analyzed using PE 5700 Analysis software, and the ratios of the density of Cbfa 1 and OC to $\beta$-actin were then calculated.

\section{Detection of protein expression of bone morphogenetic protein receptor-I (BMPR-I), BMPR-II, Smad1, Smad5, phosphorylated (p) Smad1, pSmad5, Smad4, Smad6, and Cbfa1 by western blotting}

The fibroblasts at passage 3 were prepared into a singlecell suspension before the addition of the cell lysis buffer followed by the determination of protein mass. Sodium dodecyl sulphate-polyacrylamide gel electrophoresis was used to evaluate $80 \mu \mathrm{g}$ of protein gained from individual groups overall before transportation to a nitrocellulose filter(NC) membrane. 5\% non-fat milk was utilised to shut off the NC membrane for 1 hour before incorporated with primary antibody (Santa Cruz, Danvers, MA, USA) and reacted in a $4{ }^{\circ} \mathrm{C}$ environment throughout the night. Tris Buffered saline Tween (TBST) was applied to rinse the membrane 3 times each for 5 minutes the next day. Following rinsing of the membrane, a secondary antibody (Beijing Zhongshan Golden Bridge, Beijing, China) was incorporated and underwent a 1 hour incubation period. TBST was used to rinse the membrane 3 times and developed. Bio-Rad Quantity One analysis software (Bio-Rad, Hercules, California, USA) was used to analyse grayscale images gained with the housekeeping protein $\beta$-actin used to compare with the quantified protein in order to work out the relative intensity.

\section{Detection of protein expression of pSmad1, pSmad5, and Cbfa1 after recombinant human bone morphogenetic protein-2 (rbBMP-2) inducement by western blotting}

Normal and AS fibroblasts at passage 3 were seeded onto culture flasks, and $100 \mathrm{pg} / \mathrm{mL}$ rhBMP-2 (GenScript, Nanjing, China) was added to the fibroblast culture flasks. The flasks were placed in the $\mathrm{CO}_{2}$ incubator and incubated for $72 \mathrm{~h}$ to extract the cell proteins for western blotting. The operating was same as above.

\section{Statistical analysis}

The means and standard deviations for continuous data were worked out by using descriptive statistics. Differences between groups were determined using independent $t$-tests and SPSS version 16.0 (SPSS, Chicago, IL, USA). $\mathrm{P}<0.05$ 
indicated statistical significance.

\section{Results}

Cellular growth, morphological characteristics, and cell source identification

The survival rate was $100 \%$ for the primary cultures in all 20 cases. On days 3-5, cells appeared from tissue sections within the primary culture while after 6 to 8 days, an outgrowth was formed due to encirclement of fibroblasts with the tissue sections. Post 9 to 10 days, cells flourished and expanded to around $50 \%$ confluence with slight gaps observed among the sections. At the end of days 12 to 14, cells assembled with no gaps among the sections, however, no adhesion of the section was present. But adhension was observed after 15-17 days. The growth of cells was plentiful and steady with a net-like and bundle-like or whirl-like formation in the passages at low and high density respectively. Under a reverse microscope, the morphology of the cells was spindle-shaped, plumped cell body, even cytoplasm, round nucleus, and clear nucleolus. Indirect immunofluorescence assay was used in order to make out the source of the cells. Monoclonal antibody against vimentin was used as a stain presenting with positive results while monoclonal antibody against cytokeratin presented with negative results. This is an indication of fibroblast cells from the mesoderm (Figure 1).

\section{Proliferative characteristics of AS fibroblasts}

As shown in the cell growth curve (Figure 2), fibroblasts from AS patients proliferated much faster than those of the control group. The proliferation rate showed a difference on the second day, and the difference continued to exist and became more obvious. At day 5, fibroblasts from the AS patients proliferated $41.8 \%$ faster than in the control group.

\section{Distribution of the fibroblast cycle with $A S$}

The ratio of the cells at the G0/G1 phase of the group with AS was obviously lower than the control group $(\mathrm{P}<0.01)$, with cell ratios at the $\mathrm{S}$ phase, was moderately higher the control group $(\mathrm{P}<0.01)$. No discrepancy was observed in the ratio between the cells of the two groups at the G2/M phase. Additionally, cellular apoptotic peak formed by the hypodiploid cell mass was detected in the control group but was not detected in the group with AS (Table 1 and Figure 3).
Apoptotic rate of fibroblasts with AS detected by flow cytometry using Annexin V

Annexin $\mathrm{V}$ is a group of cellular proteins with a molecular weight of $36 \mathrm{KD}$ and is capable of binding negatively charged phospholipids in a calcium-dependent manner. Phosphatidylserine (PS) was relocated from the cytoplasmic face in the plasma membrane to the cell exterior throughout the apoptosis surface. Annexin V was used as an apoptosis detecting probe due to its powerful $\mathrm{Ca}^{2+}$-dependent affinity for PS. Our findings indicated that the apoptotic rates of the fibroblasts with AS at the early and the advanced stages, and total apoptotic rates, decreased significantly compared with those of the control group $(\mathrm{P}<0.05)$ (Table 2 and Figure 4).

\section{Detecting ALP activity, collagen synthesis and OC secretion}

ALP activity, the synthetic amount of collagen, and the secretory volumes of OC of AS fibroblasts were much higher than the control group, with significant differences among the two groups $(\mathrm{P}<0.01$ or $\mathrm{P}<0.05)$ (Table 3).

\section{Using RT-PCR to detect Cbfa 1 and OC expressed by $m R N A$}

mRNA expression of Cbfa1 in normal fibroblasts was extremely low, while that in AS fibroblasts increased obviously with moderate discrepancy among the 2 groups $(\mathrm{P}<0.001)$. OC expressed in AS fibroblast mRNA was mammoth when compared with normal fibroblasts $(\mathrm{P}<0.01)$ (Table 4).

\section{Detection of protein expression of Cbfa $1, B M P$ receptors, and Smads}

Compared with normal hip capsule fibroblasts, the expression of Cbfa 1 significantly increased in AS hip capsule fibroblasts. The expression of BMPR-I and BMPR-II in AS fibroblasts was also much higher than in normal fibroblasts. Normal and AS fibroblasts both contained Smad1 and Smad5 proteins, but the expressed levels of this within AS fibroblasts towered when compared with normal fibroblasts. Normal and AS fibroblasts both expressed pSmad 1 and $\mathrm{pSmad} 5$ proteins, but their expression levels were very low; grey level analysis showed that the relative grey levels of pSmad1 and pSmad5 in AS fibroblasts were much higher than in normal fibroblasts. The expression of common-partner Smad (Co-Smad) (Smad4) in normal fibroblasts was not significant but 

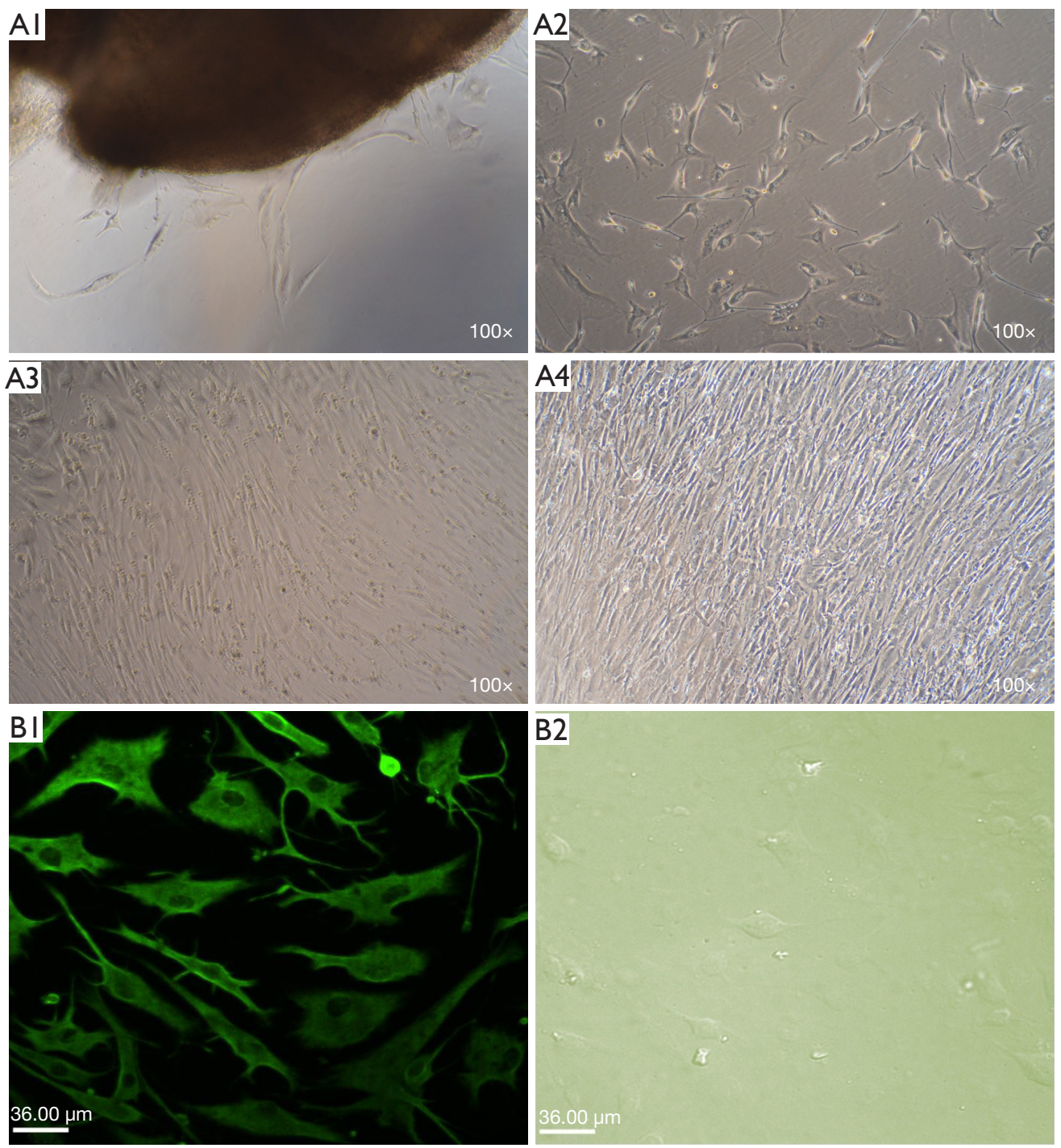

Figure 1 Growth status and cell source identification of fibroblasts. (A1,A2,A3,A4) Show the growth status of fibroblasts. Cells emerged from tissue pieces (A1). Cells were spindle or polygon and diffused outward (A2). Cells thrived and grew to nearly 50\% confluence (A3). Cells closely adhered to each other (A4). Cell source identification with indirect immunofluorescence assay (B1,B2). Anti-vimentin antibody stain showed positive results (B1) while anti-cytokeratin antibody stain showed negative results (B2), verifying mesoderm origin of fibroblasts cells.

was in AS fibroblasts. The expression of inhibitory Smad (I-Smad) (Smad6) in AS fibroblasts were not significant, but was in normal fibroblasts (Figure 5).

\section{Detection of protein expression of pSmad1, pSmad5, and Cbfa1 after rbBMP-2 inducement}

pSmad1, pSmad5, and Cbfa1 that are expressed in normal and AS fibroblasts stimulated by rhBMP-2 was significantly increased, indicating that BMP-2 can activate the BMP/ Smads signal transduction pathway in fibroblasts (Figure 6).

\section{Discussion}

Autoimmune disease is fairly common and one that has an excessive degree of disability, cerebral and peripheral joint ossification as the main cause is Ankylosing spondylitis (AS). To investigate the pathological osteogenic molecular 
mechanism, it is necessary to determine the target cells involved in osteogenic differentiation first.

AS ossification involves the connective tissues around the spine and joints; with fibroblasts being the most abundant in connective tissues and are derived from primitive mesenchyme. $(15,16)$. Fibroblasts are key in repairing

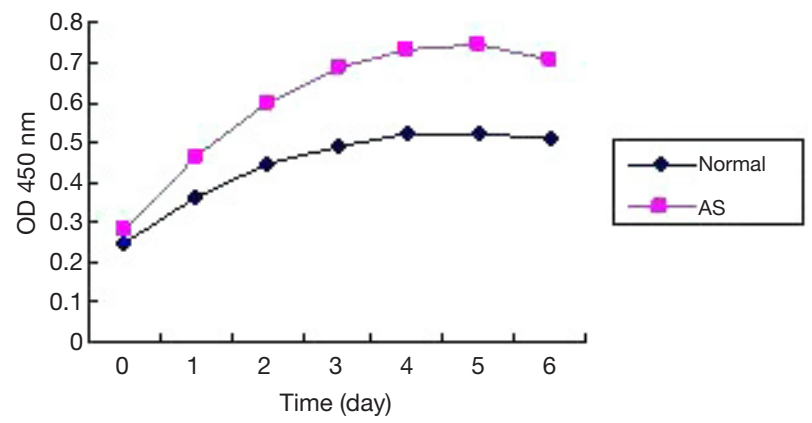

Figure 2 Cell growth curve of ankylosing spondylitis (AS) and normal fibroblasts. Proliferation of fibroblasts from AS patients demonstrated abnormal activity.

Table 1 Distribution of the fibroblast cycle $(x \pm s)$

\begin{tabular}{lccc}
\hline \multirow{2}{*}{ Group } & \multicolumn{3}{c}{ Phase } \\
\cline { 2 - 4 } & G0/G1 & S & G2/M \\
\hline Control group & $79.153 \pm 3.507$ & $7.477 \pm 2.546$ & $13.37 \pm 1.506$ \\
Ankylosing & $60.73 \pm 1.784^{\star \star}$ & $25.587 \pm 3.775^{\star *}$ & $13.683 \pm 2.057$ \\
spondylitis group & & & \\
\hline
\end{tabular}

Compared with control group: **, $\mathrm{P}<0.01$.

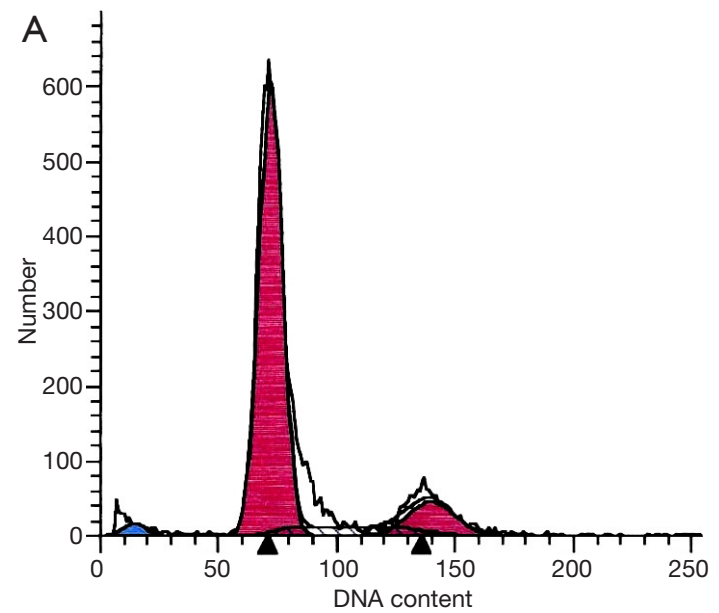

trauma and pathological ectopic ossification. This is due to its main function being in charge of extracellular matrix replacement and manufacturing that is loaded with various macromolecules and collagen $(16,17)$.

Fibroblasts and osteoblasts are of the same lineage. Cbfa 1 and $O C$ are genes that exist and expressed in osteoblasts but not fibroblasts (2). Cbfa1 has a major role in regulating osteogenic differentiation due to it being a critical transcription agent. It has also been proven to have a role in regulating additional differentiation marker and phenotyperelated genes for the promotion of differentiation and bone production. In the promoter of OC and collagen I, there are osteoblast-specific cis-acting elements (OSEs). Cbfa 1 can specifically bind to OSEs and enhance the expression of OC and collagen I $(7,8)$. Thus, the Cbfa1 expressed could be a fibroblast osteogenic differentiation tag.

Additionally, osteogenic differentiation can be identified based on osteoblast-specific secretory proteins and extracellular matrix mineralization ability. Three important osteogenic phenotypes are reflecting osteogenic

Table 2 Apoptotic rate of fibroblasts (\%) $(\bar{x} \pm s)$

\begin{tabular}{|c|c|c|c|}
\hline Group & $\begin{array}{l}\text { Early apoptotic } \\
\text { rate }\end{array}$ & $\begin{array}{l}\text { Late apoptotic } \\
\text { rate }\end{array}$ & $\begin{array}{l}\text { Total apoptotic } \\
\text { rate }\end{array}$ \\
\hline Control group & $4.783 \pm 1.367$ & $4.83 \pm 1.503$ & $9.613 \pm 1.982$ \\
\hline $\begin{array}{l}\text { Ankylosing } \\
\text { spondylitis group }\end{array}$ & $1.523 \pm 0.257^{*}$ & $1.713 \pm 0.153^{*}$ & $3.237 \pm 0.135^{\star}$ \\
\hline
\end{tabular}

Compared with control group: *, $\mathrm{P}<0.05$.

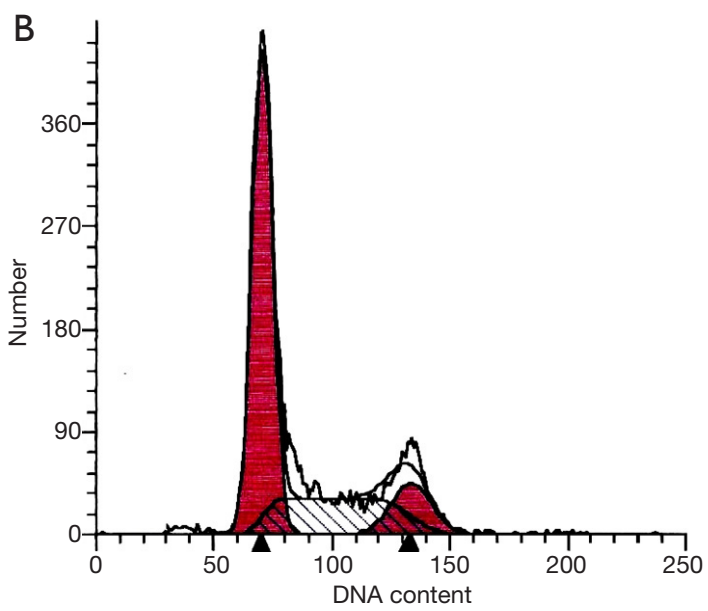

Figure 3 Cell cycle of normal and AS fibroblasts. (A) Cell cycle of normal fibroblasts; (B) cell cycle diagram of ankylosing spondylitis (AS) fibroblasts. Cellular apoptotic peak formed by the hypodiploid cell mass was detected in the control group, but not in the AS group. 


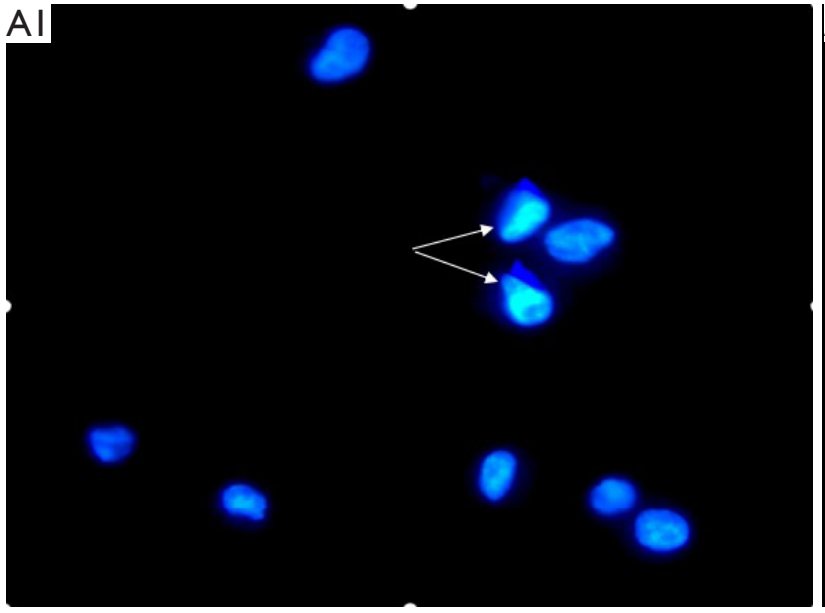

$\mathrm{BI}$

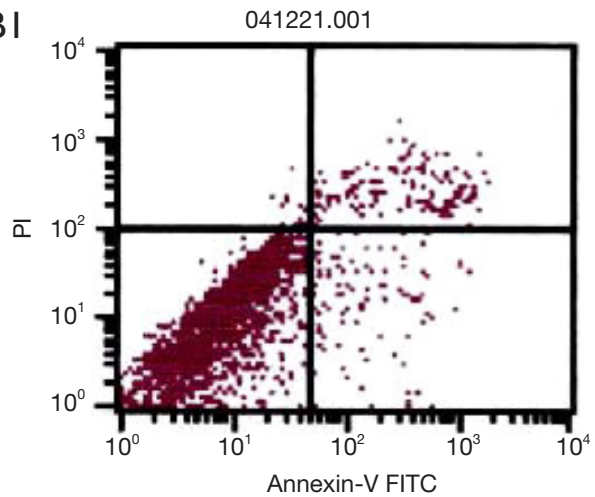

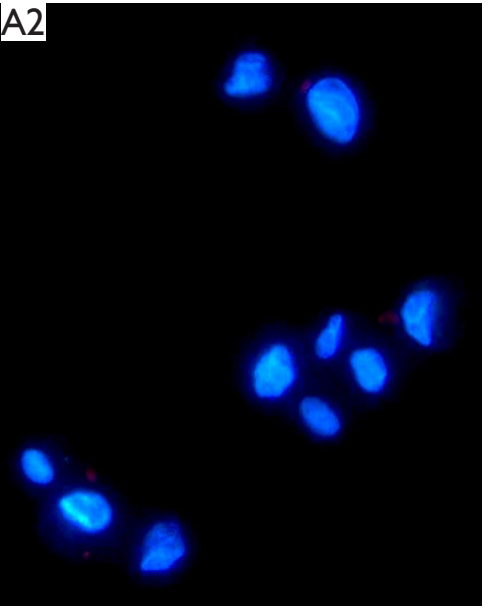

B2

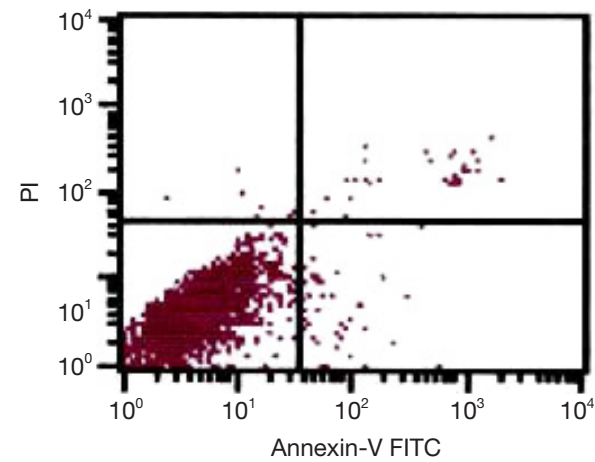

Figure 4 Apoptotic rate of normal and ankylosing spondylitis (AS) fibroblasts. (A) Cell morphology of fibroblasts with fluorescence staining ( $\times 200)$; the arrows indicate apoptotic cells. (B) Apoptotic rate of normal and AS fibroblasts. Apoptotic cell was smaller, fluorescent intensity increased, nuclear was shrinkage, and nucleolus disappeared (A1). There were more apoptotic cells in the control group (B1) than in the AS group (B2). FITC, fluorescein isothiocyanate; PI, propidium iodide.

Table 3 ALP activity, collagen synthesis and osteocalcin secretion $(\bar{x} \pm s)$

\begin{tabular}{lccc}
\hline Group & ALP $(\mu / \mathrm{g})$ & Collagen (OD) & $\begin{array}{c}\text { Osteocalcin } \\
(\mu \mathrm{g} / \mathrm{L})\end{array}$ \\
\hline Control group & $17.85 \pm 2.03$ & $0.071 \pm 0.014$ & $5.5 \pm 1.277$ \\
Ankylosing & $24.16 \pm 3.03^{\star *}$ & $0.097 \pm 0.008^{\star *}$ & $8.4 \pm 2.113^{*}$ \\
spondylitis group & & & \\
\hline
\end{tabular}

In comparison with the control group: ${ }^{*}, \mathrm{P}<0.05$; ${ }^{* *}, \mathrm{P}<0.01$. ALP, alkaline phosphatase; OD, optical density, $450 \mathrm{~nm}$.

Table 4 mRNA expression of Cbfa 1 and OC $(\bar{x} \pm s)$

\begin{tabular}{lcc}
\hline Group & Cbfa1/ $\beta$-actin & OC/ $\beta$-actin \\
\hline Control group & $0.173 \pm 0.057$ & $1.51 \pm 0.711$ \\
Ankylosing spondylitis group & $1.060 \pm 0.165^{\star \star *}$ & $5.27 \pm 0.966^{\star *}$ \\
\hline
\end{tabular}

In comparison with the control group: ${ }^{* *}, \mathrm{P}<0.01$; ${ }^{* *}, \mathrm{P}<0.001$. Cbfa1, core-binding factor a1; OC, osteocalcin. differentiation. An advanced osteoblast differentiation marker that is related to matrix mineral formation is ALP. A matrix protein integrated by osteoblasts is Type I collagen and has the ability to change into a mineralized stage with the addition of hydroxyapatite in late osteogenesis phases. OC has major abundancy as a non-collagenous matrix protein present in the bone that has an association with bone mineral.

We investigated the expression of osteogenic differentiation marker genes and osteogenic phenotypes in AS fibroblasts. The findings indicated that $\mathrm{Cbfa} 1$ and $\mathrm{OC}$ expressed in AS fibroblastic mRNA was significantly higher when compared with the normal $(\mathrm{P}<0.001$ or $\mathrm{P}<0.01)$, suggesting that osteogenic differentiation marker genes of AS fibroblasts were highly expressed at the transcriptional level, resulting in fibroblast differentiating into osteoblasts. ALP activity, collagen synthesis, and OC secretion in 


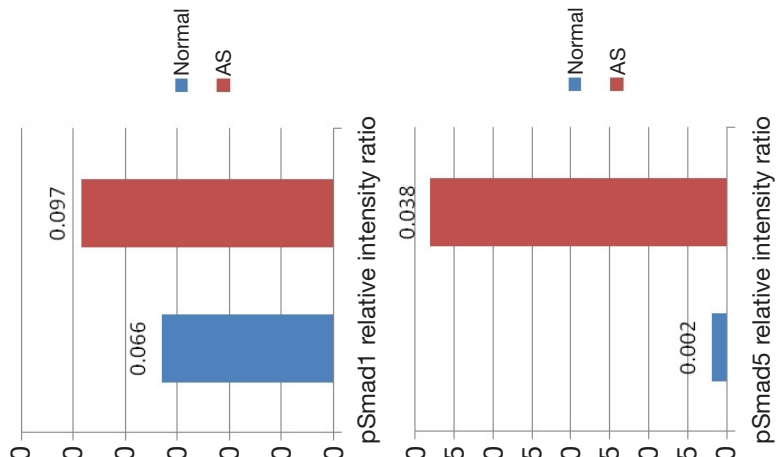

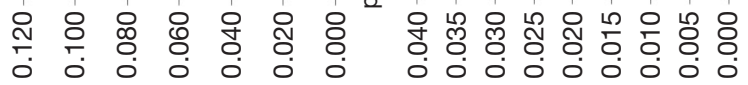
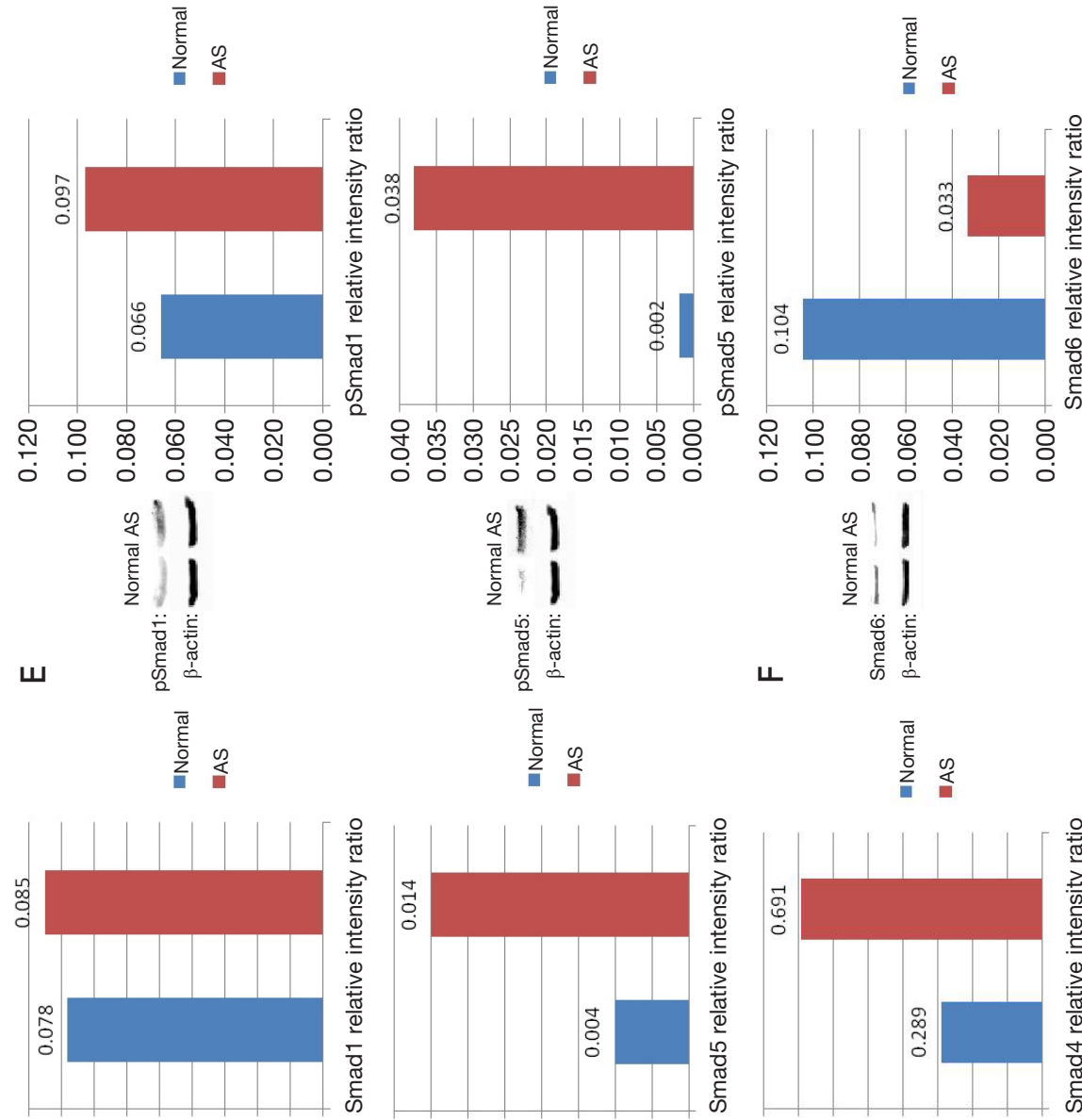

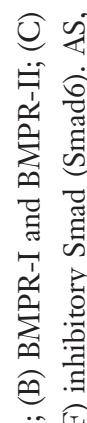

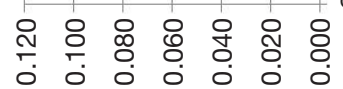

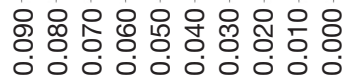
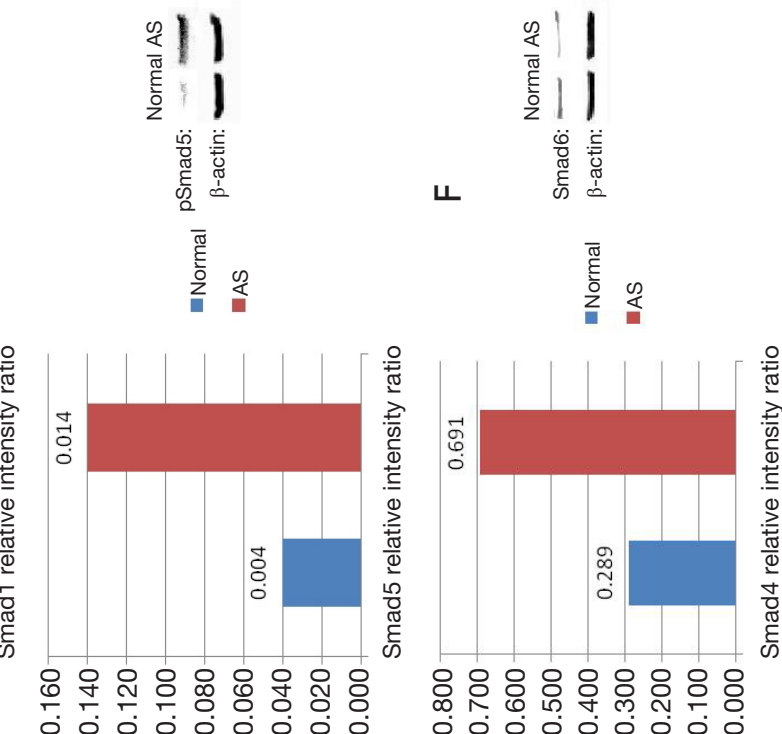

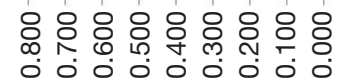
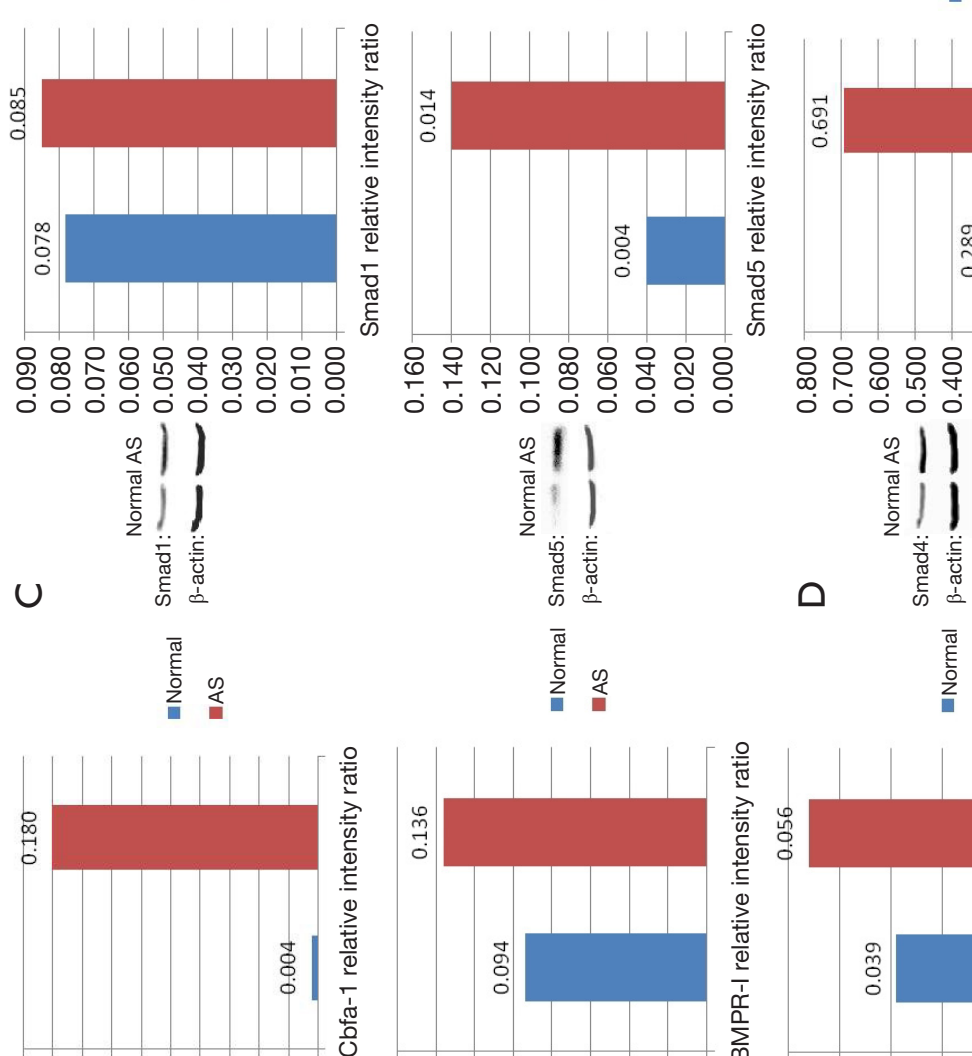

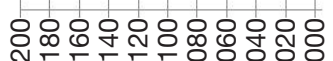

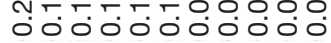

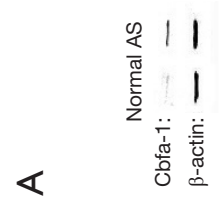

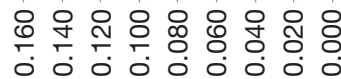
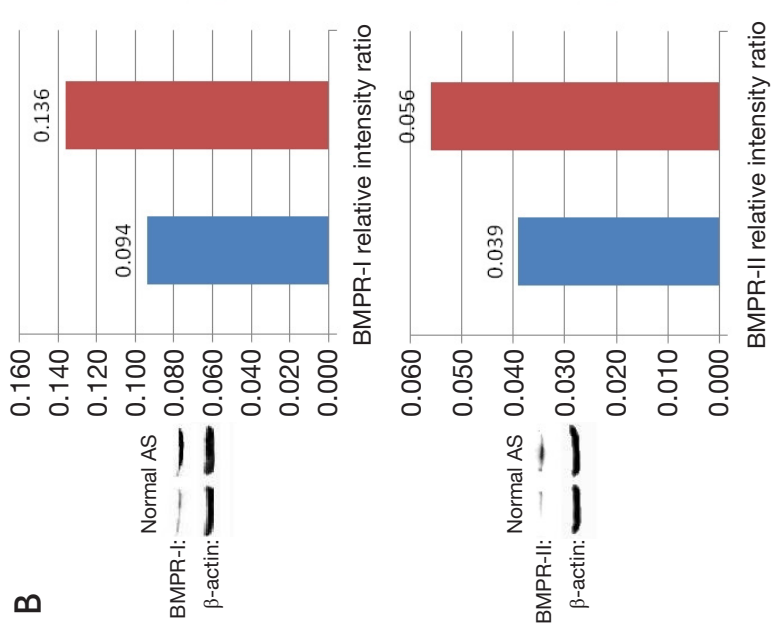

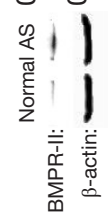

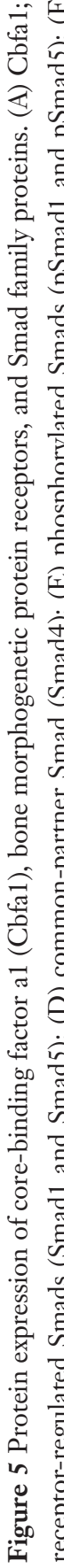



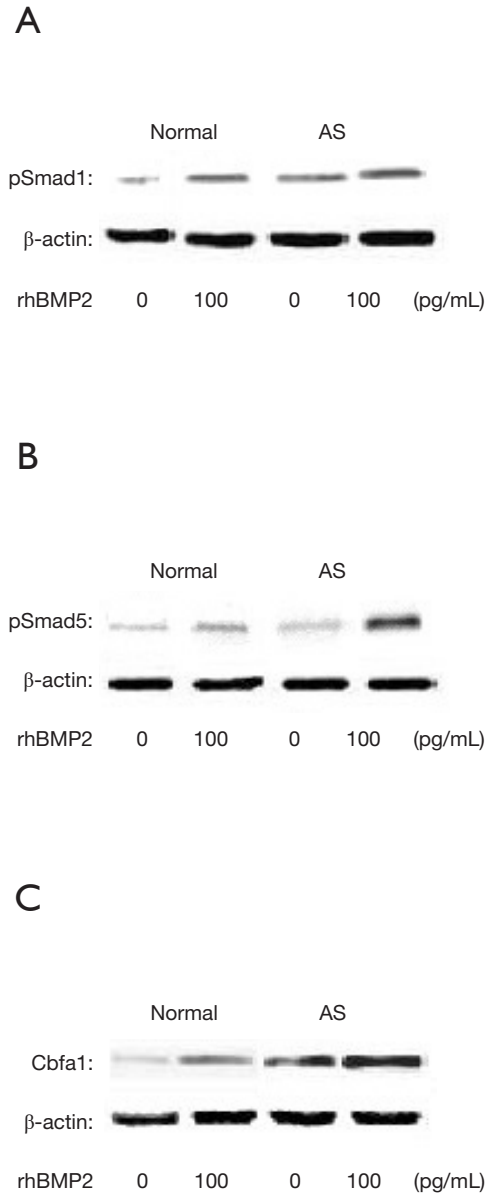
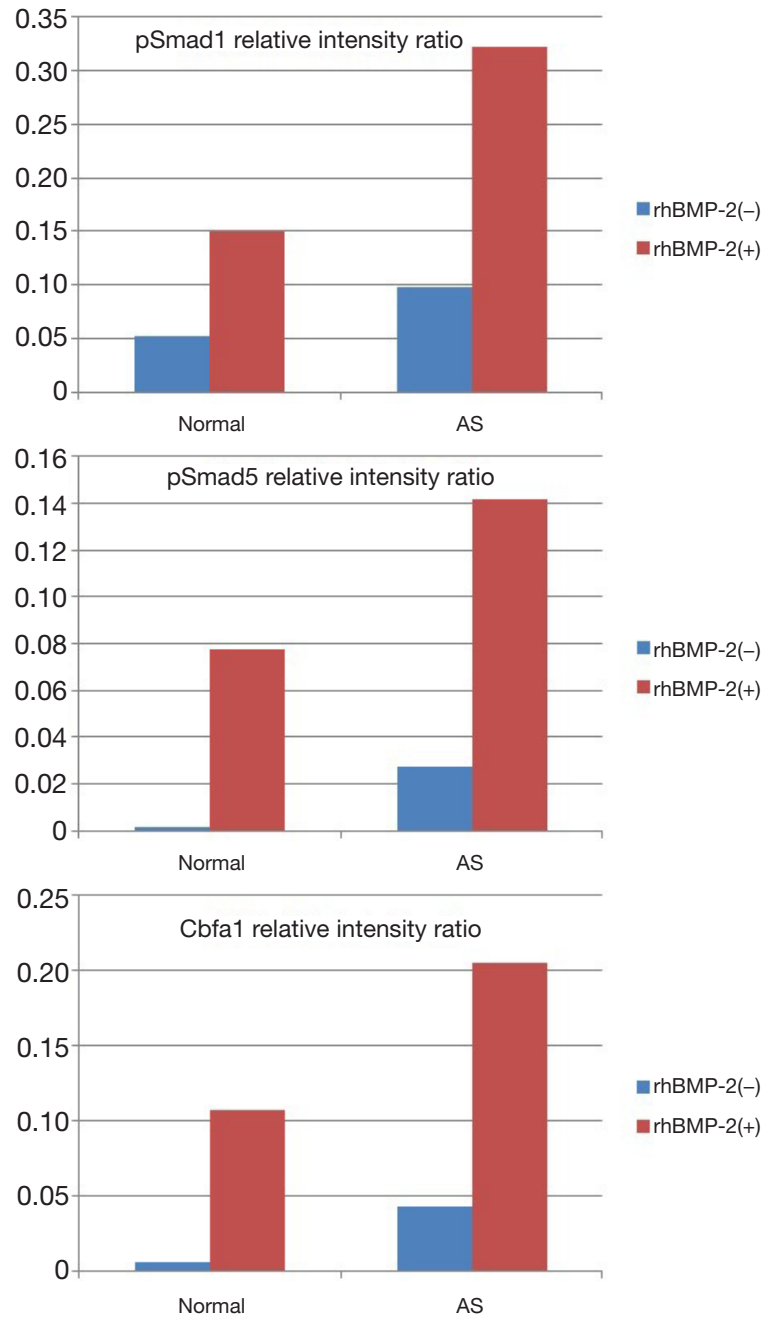

Figure 6 Protein expression of phosphorylated (p) Smad1, pSmad5, and core-binding factor a1 (Cbfa1) in normal and ankylosing spondylitis (AS) fibroblasts after rhBMP-2 inducement. (A) pSmad1; (B) pSmad5; (C) Cbfa1. rhBMP, recombinant human bone morphogenetic protein.

supernatants of cultured AS fibroblasts were higher when compared with supernatants of normal fibroblasts $(\mathrm{P}<0.01$ or $\mathrm{P}<0.05)$, indicating that AS fibroblasts have strong secretory properties. These observations further indicated the similar biologic properties of fibroblasts and osteoblasts. AS fibroblasts are important target cells that play important roles in local ossification in AS. The development of organisms depends on precise cooperation between cellular proliferation, differentiation, and apoptosis. The balance between cellular proliferation and apoptosis is an important element for maintaining homeostasis of multi-cellular organisms. However, our study showed that the proliferative activity of AS fibroblasts was abnormally high and the apoptotic rate decreased, which may be an important factor for further accelerating AS ossification.

As the target cells of AS ossification, the activation of fibroblasts' osteogenic potential depends on the stimulation of particular cytokines. Cbfa 1 expressed in fibroblasts is dependent on upstream signalling molecule regulation. BMPs that go with the transforming growth factor- $\beta$ (TGF- $\beta$ ) superfamily possess greatly identified tasks in mammalian development bone production. They promote the production of bone and cartilage by encouraging differentiation of mesenchymal cells and therefore is regarded as a strong growth factor (18). BMP-2 is considered to be the most active $\mathrm{BMP}$ and can induce osteogenesis alone. The promoter of BMP-2 has the binding sequence of Cbfa 1 and can induce the transcription of Cbfa1 in vitro in cultured osteoblasts and 
chondrocytes $(19,20)$.

Smad family proteins are paramount in the cell membrane to the nucleus as well as being mediators in the BMP signalling transduction process $(21,22)$. In vertebrates, at least $8 \mathrm{Smad}$ proteins have been found, and are divided into three categories as follows: (I) receptor-regulated Smad (R-Smad): Smad1, Smad5, Smad8 are involved in BMP signal transduction, and $\mathrm{Smad} 2$ and $\mathrm{Smad} 3$ participate in TGF- $\beta$ or activin signalling transduction; (II) Co-Smad: Smad4 is the sole regular Smad for TGF- $\beta$ and BMP signalling; and (III) I-Smad: Smad6 inhibits BMP signal transduction, and Smad7 inhibits TGF- $\beta$ and BMP signal transduction.

The BMP signal transduction process can be summarized as follows (21-24): BMP signalling starts by the transmission of signals through the plasma membrane by forming heteromeric complexes that are characteristic type I and type II serine/threonine kinase receptors. The next step involves the phosphorylation of type I receptors before type II is activated. Phosphorylated Smad proteins, R-Smads (Smad1, Smad5, and Smad8) begin the intracellular signalling process via type I receptor activation. A complex is formed with Co-Smad ( $\mathrm{Smad} 4)$ via $\mathrm{R}-\mathrm{Smads}$ activation and heterologous complexes enter the nucleus and regulate transcription of target genes.

Smad1 and Smad5 are classified specifically as BMP intracellular signal transduction molecules. They are able to send BMP messages to the nucleus as well as control target genes expressed during transduction by combining with Smad4 a linked intermediary molecule (25). Cbfa1 can bind to activated Smad1 and Smad5 physically for osteoblast differentiation stimulation (26). Smad4 is the shared intermediary molecule in the BMP and TGF- $\beta$ transduction pathway. In the experiment of osteogenic differentiation of C2C12 mesenchymal cells induced by BMP-2, the complex formation of Smad5 and Smad4 is a key step in the BMP signal transduction pathway (27). Smad4 conditionally deleted in osteoblasts precedes to decreased bone mineral density, volume, formation rate, and osteoblasts quantity (28). Smad6 is required to limit BMP signalling during endochondral bone formation, which plays a negative role in BMP signal transduction by combining with bone morphogenetic protein receptor-I(BMPR-I) or Smad1 (to compete with Smad4) to form an inactive complex (29-31).

We further observed the protein expression of the BMP/ Smads signalling pathway in AS fibroblasts. The findings indicated that there's the amount of BMP specific receptors (BMPR-I and BMPR-II) in AS fibroblasts, confirming that fibroblasts are target cells of BMP signalling. The protein expression of Cbfa1, pSmad1, and pSmad5 in AS fibroblasts were higher compared to the control group. The unphosphorylated Smad1, Smad5, and Smad4 expressed was also higher than the control group, indicating that a highly activated BMP/Smad signal transduction pathway exists in AS hip capsule fibroblasts. However, the expression of Smad6 was lower than in the normal control group, indicating that AS fibroblasts lack the self-regulatory ability and cannot inhibit the transduction of BMP signalling. The pSmad1, pSmad5 and Cbfa1 expressed in normal and AS fibroblasts stimulated by rhBMP-2 was significantly increased, indicating that BMP-2 can specifically bind to $\mathrm{BMP}$ receptors and induce fibroblast differentiation into osteoblasts by activating the $\mathrm{BMP} / \mathrm{Smads}$ signal transduction pathway.

In conclusion, the present study showed that fibroblasts cultured in vitro, derived from hip joint capsules of patients with AS, have the biologic characteristics of osteogenic differentiation. Osteogenic marker genes and osteogenic phenotypes were highly expressed in AS fibroblasts, which confirmed that AS fibroblasts are important target cells of AS ossification. RhBMP-2 can make BMP/Smad pathway in normal fibroblasts activated and enhance the activation degree of BMP/Smad pathway in AS fibroblasts, indicating that BMP is an important initiation factor inducing AS fibroblast osteogenic differentiation. The activation of the $\mathrm{BMP} / \mathrm{Smad}$ signal transduction pathway was a potential mechanism of AS fibroblast differentiation into osteoblasts, and possibly an ossification mechanism for AS.

\section{Acknowledgments}

We would like to thank the Arthritis Clinic and Research Centre of Peking University People's Hospital and Peking University Third Hospital Orthopedic Department for providing the hip joint capsule specimens. We would also like to thank Professor Rou-Li Zhou and Professor Li Li of Peking University Medical Department for their assistance with the cell culture.

Funding: The present study was supported by the National Natural Science Foundation of China (Grant No. 30472277), the National Natural Science Foundation of China (Grant No. 30801507).

\section{Footnote}

Reporting Checklist: The authors have completed the MDAR 
checklist. Available at http://dx.doi.org/10.21037/atm-207817

Data Sharing Statement: Available at http://dx.doi. org/10.21037/atm-20-7817

Conflicts of Interest: All authors have completed the ICMJE uniform disclosure form (available at http://dx.doi. org/10.21037/atm-20-7817). The authors have no conflicts of interest to declare.

Ethical Statement: The authors are accountable for all aspects of the work in ensuring that questions related to the accuracy or integrity of any part of the work are appropriately investigated and resolved. All procedures performed in this study involving human participants were in accordance with the Declaration of Helsinki (as revised in 2013). The study was approved by the Ethics Committee of Guang'anmen Hospital, China Academy of Chinese Medical Sciences (No.: 2011-028). And all patients provided signed informed consent.

Open Access Statement: This is an Open Access article distributed in accordance with the Creative Commons Attribution-NonCommercial-NoDerivs 4.0 International License (CC BY-NC-ND 4.0), which permits the noncommercial replication and distribution of the article with the strict proviso that no changes or edits are made and the original work is properly cited (including links to both the formal publication through the relevant DOI and the license). See: https://creativecommons.org/licenses/by-nc-nd/4.0/.

\section{References}

1. Simone D, $\mathrm{Al}$ Mossawi MH, Bowness P. Progress in our understanding of the pathogenesis of ankylosing spondylitis. Rheumatology (Oxford) 2018;57:vi4-vi9.

2. Ducy P, Schinke T, Karsenty G. The osteoblast: a sophisticated fibroblast under central surveillance. Science 2000;289:1501-4.

3. Ikegame M, Ishihashi O, Yoshizawa T, et al. Tensile stress induces bone morphogenetic protein 4 in preosteoblastic and fihroblastic cells, which later differentiate into osteoblasts leading to osteogenesis in the mouse calvariae in organ culture. J Bone Miner Res 2001;16:24-32.

4. Rutherford RB, Moalli M, Franceschi RT, et al. Bone morphogenetic protein-transduced human fibroblasts convert to osteoblasts and form bone in vivo. Tissue Eng
2002;8:441-52.

5. Komori T. Regulation of osteoblast differentiation by transcription factors. J Cell Biochem 2006;99:1233-9.

6. Harada H, Tagashira S, Fujiwara M, et al. Cbfa1 isoforms exert functional differences in osteoblast differentiation. J Biol Chem 1999;274:6972-8.

7. Banerjee C, Hiebert SW, Stein JL, et al. An AML-1 consensus sequence binds an osteoblast-specific complex and transcriptionally activates the osteocalcin gene. Proc Natl Acad Sci U S A 1996;93:4968-73.

8. Kern B, Shen J, Starbuck M, et al. Cbfa1 contributes to the osteoblast-specific expression of type I collagen genes. J Biol Chem 2001;276:7101-7.

9. Nishimura R, Hata K, Matsubara T, et al. Regulation of bone and cartilage development by network between BMP signaling and transcription factors. J Biochem 2012;151:247-54.

10. Ripamonti U. Soluble osteogenic molecular signals and the induction of bone formation. Biomaterials 2006;27:807-22.

11. Yoon BS, Lyons KM. Multiple functions of BMPs in chondrogenesis. J Cell Biochem 2004;93:93-103.

12. Huang Z, Ren PG, Ma T, et al. Modulating osteogenesis of mesenchymal stem cells by modifying growth factor availability. Cytokine 2010;51:305-10.

13. Noël D, Gazit D, Bouquet C, et al. Short-term BMP2 expression is sufficient for in vivo osteochondral differentiation of mesenchymal stem cells. Stem Cells 2004;22:74-85.

14. Kang M, Bok J, Deocaris CC, et al. Hoxc8 represses BMPinduced expression of Smad6. Mol Cells 2010;29:29-33.

15. Togo S, Sato T, Sugiura H, et al. Differentiation of embryonic stem cells into fibroblast-like cells in threedimensional type I collagen gel cultures. In Vitro Cell Dev Biol Anim 2011;47:114-24.

16. Ogawa M, LaRue AC. Origin of fibroblast colony-forming units. Exp Hematol 2007;35:1319-20.

17. Schett $\mathrm{G}$. Bone formation versus bone resorption in ankylosing spondylitis. Adv Exp Med Biol 2009;649:114-21.

18. Nishimura R, Hata K, Ikeda F, et al. Signal transduction and transcriptional regulation during mesenchymal cell differentiation. J Bone Miner Metab 2008;26:203-12.

19. Banerjee C, Javed A, Chou JY, et al. Differential regulation of the two principal Runx2/Cbfa1 N-terminal isoforms in response to bone morphogenetic protein-2 during development of the osteoblast phenotype. Endocrinology 2001;142:4026-39.

20. Takazawa Y, Tsuji K, Nifuji A, et al. An osteogenesisrelated transcription factor, core-binding factor $\mathrm{A} 1$, is 
constitutively expressed in the chondrocytic cell line TC6, and its expression is upregulated by bone morphogenetic protein-2. J Endocrinol 2000;165:579-86.

21. Miyazono K, Maeda S, Imamura T. BMP receptor signaling: transcriptional targets, regulation of signals, and signaling cross-talk. Cytokine Growth Factor Rev 2005;16:251-63.

22. Miyazono K, Kamiya Y, Morikawa M. Bone morphogenetic protein receptors and signal transduction. J Biochem 2010;147:35-51.

23. Wagner DO, Sieber C, Bhushan R, et al. BMPs: from bone to body morphogenetic proteins. Sci Signal 2010;3:mr1.

24. Yi JJ, Barnes AP, Hand R, et al. TGF-beta signaling specifies axons during brain development. Cell 2010;142:144-57.

25. Kawabata M, Imamura T, Miyazoho K. Signal transduction by bone morphogenetic proteins. Cytokine Growth Factor Rev 1998;9:49-61.

26. Nishimura R, Hata K, Harris SE, et al. Core-binding factor alpha 1 (Cbfa1) induces osteoblastic differentiation

Cite this article as: Jiang N, Liu HX, Liang HY, Feng XH, Liu BY, Zhou YY. Osteogenic differentiation characteristics of hip joint capsule fibroblasts obtained from patients with ankylosing spondylitis. Ann Transl Med 2021;9(4):331. doi: 10.21037/atm-20-7817 of $\mathrm{C} 2 \mathrm{C} 12$ cells without interactions with Smad1 and Smad5. Bone 2002;31:303-12.

27. Kawai S, Faucheu C, Gallea S, et al. Mouse smad8 phosphorylation downstream of BMP receptors ALK-2, ALK-3, and ALK-6 induces its association with Smad4 and transcriptional activity. Biochem Biophys Res Commun 2000;271:682-7.

28. Tan X, Weng T, Zhang J, et al. Smad4 is required for maintaining normal murine postnatal bone homeostasis. J Cell Sci 2007;120:2162-70.

29. Massagué J, Chen YG. Controlling TGF-beta signalling. Genes Dev 2000;14:627-44.

30. Massagué J, Wotton D. Transcriptional control by the TGF-beta/Smad signaling system. EMBO J 2000;19:1745-54.

31. Estrada KD, Retting KN, Chin AM, et al. Smad6 is essential to limit BMP signaling during cartilage development. J Bone Miner Res 2011;26:2498-510.

(English Language Editor: R. Scott) 